\title{
Market, Testbed, Backroom: The Redacted Internet of Facebook's Discover
}

\author{
Lucy Pei* \\ lucyp1@uci.edu \\ University of California, Irvine \\ Irvine, California, USA
}

\author{
Benedict Salazar Olgado* \\ bolgado@uci.edu \\ University of California, Irvine \\ Irvine, California, USA \\ University of the Philippines, Diliman \\ Quezon City, Metro Manila \\ Philippines
}

\author{
Roderic Crooks \\ University of California, Irvine \\ Irvine, USA
}

\begin{abstract}
This paper uses document theory to analyze Discover, a partially free-to-use application developed by Facebook's philanthropic initiative Connectivity and released in the Philippines in May 2020. Discover's design is predicated on the conviction that access to valorized forms of technology-in this case, popular websites viewed via the Internet-promises benefits to marginalized users who are presumed to lack resources needed to fully participate in contemporary informational capitalism. Document theory in HCI provides a framework that allows us to analyze the most popular websites as rendered by Discover. We argue that Discover's logic of redaction and form moderation reproduces the very structural inequality that access to the Internet frequently claims to ameliorate. We conclude by pointing to potential applications of our approach in research at the intersection of HCI, ICT4D, and political economy.
\end{abstract}

\section{CCS CONCEPTS}

- Human-centered computing $\rightarrow$ Empirical studies in $\mathrm{HCI}$.

\section{KEYWORDS}

Connectivity, access, document theory, political economy, the Philippines

\section{ACM Reference Format:}

Lucy Pei, Benedict Salazar Olgado, and Roderic Crooks. 2021. Market, Testbed, Backroom: The Redacted Internet of Facebook's Discover. In CHI Conference on Human Factors in Computing Systems (CHI '21), May 813, 2021, Yokohama, Japan. ACM, New York, NY, USA, 13 pages. https: //doi.org/10.1145/3411764.3445754

\section{INTRODUCTION}

Following Mark Zuckerberg's 2013 declaration that "connectivity is a human right," [82] Facebook, like other multinational technology companies, has sought to bring versions of its services to developing markets across the globe. A string of projects, organized largely under the aegis of the company's Connectivity initiative, has brought

${ }^{*}$ Both authors contributed equally to this research.

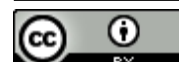

This work is licensed under a Creative Commons Attribution International 4.0 License.

CHI '21, May 8-13, 2021, Yokohama, Japan

(C) 2021 Copyright held by the owner/author(s)

ACM ISBN 978-1-4503-8096-6/21/05.

https://doi.org/10.1145/3411764.3445754 a succession of products and services to bear on "challenges of accessibility, affordability, and relevance" in 63 countries across Asia, Africa, and South America. Facebook Connectivity's most recent initiative, Discover, was launched in May 2020 in several countries including the Republic of the Philippines ${ }^{1}$. Discover takes the form of a "mobile web and Android app that enables people to browse any site on the internet using a daily balance of free data from their mobile operator" [18]. The debut of Discover occurs amid ongoing, pointed criticism of Facebook's Connectivity efforts by researchers in $\mathrm{HCI}$ and ICT4D, who have contrasted the putatively altruistic vision of these services with the extractive business models they pursue, the exploitative privacy policies they enforce, and the limited, proprietary, walled-garden version of Internet access they provide $[9,11,32,46,75]$. At the same time, other researchers have valorized Connectivity's efforts, arguing collectively that even a limited or constrained version of Internet access in perpetually marginalized states benefits users more than the next most likely option: to have no access at all $[38,79]$.

While much of the research to date on Facebook Connectivity's many and varied approaches to serving the Global South ${ }^{2}$ turns on moral claims about whether or not these efforts support or exploit the promise of Internet access, we develop here a different approach, one predicated on the commitment that access to a given form of digital technology necessarily entails an exchange of resources. If, as Pei and Crooks have argued, access to technology in sites of structural inequality should be viewed as the simultaneous configuration of benefits and costs, then strictly normative assessments can only provide a partial view of a more complex sociotechnical phenomenon [53]. To provide a richer analysis, we draw on document theory, a set of terms, tools, and empirical methods frequently associated with documentation studies [14, 20, 40] and adapted for use in HCI [47, 48]. In a purposeful inversion, we supplement studies of how access affects users for good or ill with empirical contextualization of how access situates users in economic and political relationships.

Our paper makes three contributions: first, building on methods developed for a previous study of commercial social media [47], we use HCI-focused tools from document theory (i.e., agent, means,

\footnotetext{
${ }^{1}$ See Figure 1 for a history of Facebook's internet engagements in the Philippines, including the launch of Discover's predecessor, Free Basics. See Table 2 for a comparison of Free Basics and Discover.

${ }^{2}$ We use the term Global South to shift focus away from development and cultural difference and towards recognizing the importance of geopolitical relations. The term calls for solidarity against hegemonic forces that threaten the autonomy of particular countries.
} 
modes, and results) to analyze the rendering on Discover of the most popular websites in the Philippines in August of 2020. Based on this analysis, we argue that Discover's logic of redaction and form moderation reproduces the very structural inequality that access to the Internet frequently claims to ameliorate. Second, we add to an emerging literature on the importance of the Philippines as a hub of global informational capitalism, not merely as an emerging market ready for external investment, but as a testbed for product development already enmeshed in global networks of labor and capital. Third, our approach foregrounds political economy in the methods, theories, and designs of $\mathrm{HCI}$ research and so represents an attempt to "deeply consider computing and its relationship to the shaping power of the economy" [23].

In the section that follows, we place scholarly responses to Facebook's Connectivity efforts-particularly Discover's immediate predecessor, Free Basics-alongside works that sketch out the contours of Internet access in the Philippines. We begin our review in the Philippines, arguing that Facebook has made the country into its market, testbed, and backroom. We then characterize prior work focused on Free Basics in a variety of locations, showing how this research portrays configurations of access as better than nothing, inadequate, or able to be improved by design.

\section{RELATED WORK}

\subsection{The Philippines as Facebook's Market, Testbed, and Backroom}

With a $72.1 \%$ internet penetration rate [70] and a highly engaged audience for digital content [29,35], the Philippines has been transformed by online connectivity [51]. The internet has connected the more than 2 million overseas Filipino workers to their families back home $[3,15]$ and has enabled a more efficient flow of remittances through online platforms [37, 42]. The Philippines is the leading offshore destination for business process outsourcing, due to transnational infrastructures, high literacy, English proficiency, and cheap labor [5]. High internet penetration and high risk for natural disasters make the Philippines a hub for digital humanitarianism [49, 77]. However, internet connectivity in the Philippines is slow despite being expensive $[43,59,76]$. A duopoly of telecommunication companies, Globe and PLDT (Smart), is seen to inhibit innovation and efficiency [76] but is aggressive in expanding its user base through microtransaction models $[6,41]$. The majority of people in the Philippines cannot afford stable broadband or postpaid mobile contracts [43] from this duopoly, leading $97 \%$ of mobile users to opt instead for pre-paid services that allow them to buy smaller credits on a per use basis [31].

Facebook enters this digital landscape which features high penetration rates and user activity on an archipelago of uneven, stratified, and precarious access that "consigns users in existing class positions, cultivates neoliberal subjects, and provides cheap network labour to the global economy" [75]. All of these make the Philippines "a perfect proving ground for Facebook's ambitions" [4]. Jackie Chang, product partnerships manager at Facebook, declared that "the Philippines will serve as a great lighthouse to other developing nations," noting the absence of resistance to the company's rapid expansion in the country [61].
As of 2020, 96\% of internet users in the Philippines have Facebook accounts with $72.5 \%$ of these users exclusively accessing the platform via a mobile phone [35]. The company has a higher penetration rate than the leading television stations in the country [17]. Its ubiquity has led Facebook to be integrated into online pedagogy [8], utilized to measure and address threats to marine wildlife [2], and used for coping mechanisms after natural disasters [73] among others. Its popularity positions Facebook as a key platform shaping not only social relations but also news and politics in the Philippines. Ong and Cabañes [50] uncover how Facebook, weaponized by a hierarchized group of political operators, is a key part of the "architecture of network disinformation" in the Philippines that sustains the power of the authoritarian president, Rodrigo Duterte. From fake news to trolls, the "sovereign trickster" [55] utilizes the platform to sustain his inhumane war on drugs and silence his opponents. Human rights groups and journalists point out that this is possible because of Facebook's unprecedented grip on the country. Facebook acts as the leading purveyor of news and information, creating an information ecosystem sold to and controlled by the highest bidder [4].

In addition to being a key market where political operators can purchase their way, the Philippines has also become a testbed for Facebook. The company experiments with changes and performs live A/B testing in the Global South as opposed to testing in wealthier markets like in the United States. From design adjustments to policy changes, "there's a peculiar callousness in Facebook using entire countries as testing grounds" [71] and then only offering tepid apologies when results prove to be harmful [26]. This puts whole populations at real risks given their precarity and dependency on Facebook for access and information, as they have no real recourse against the platform's decisions [72].

Facebook has also tapped into the Philippines as a source of cheap labor and a route for expansion, with the country operating as a backroom for the company [75]. Sarah Roberts [57] makes visible the exploitative labor practices of commercial content moderation being offshored by Facebook to the Philippines. Facebook has leveraged its ties with the Duterte administration to secure authorization to build an undersea cable network that will directly connect the United States to the Philippines [16]. Both the regime and Facebook promise that the project will provide faster, wider, and cheaper internet access to the country. Critics, however, are wary of its geopolitical ramifications as it enables Facebook's hold on the country to tighten [71].

The starting point of any document analysis is the articulation of the system's goal [48]. We have argued through our literature review that Facebook has made the Philippines into its market, testbed, and backroom. Our study takes this as a starting point in conducting a document theory analysis of Discover in the Philippines. Discover is a newly deployed and not-yet-studied application that is positioned by Facebook as the successor to Free Basics (refer to Figure 1 for a timeline of Facebook Connectivity initiatives in the Philippines). We review the body of work on Free Basics next.

\subsection{Free Basics as a Configuration of Access}

Uimone [74] analyzed a corpus of 54 texts produced by Facebook around Free Basics. The study shows that Free Basics is framed 


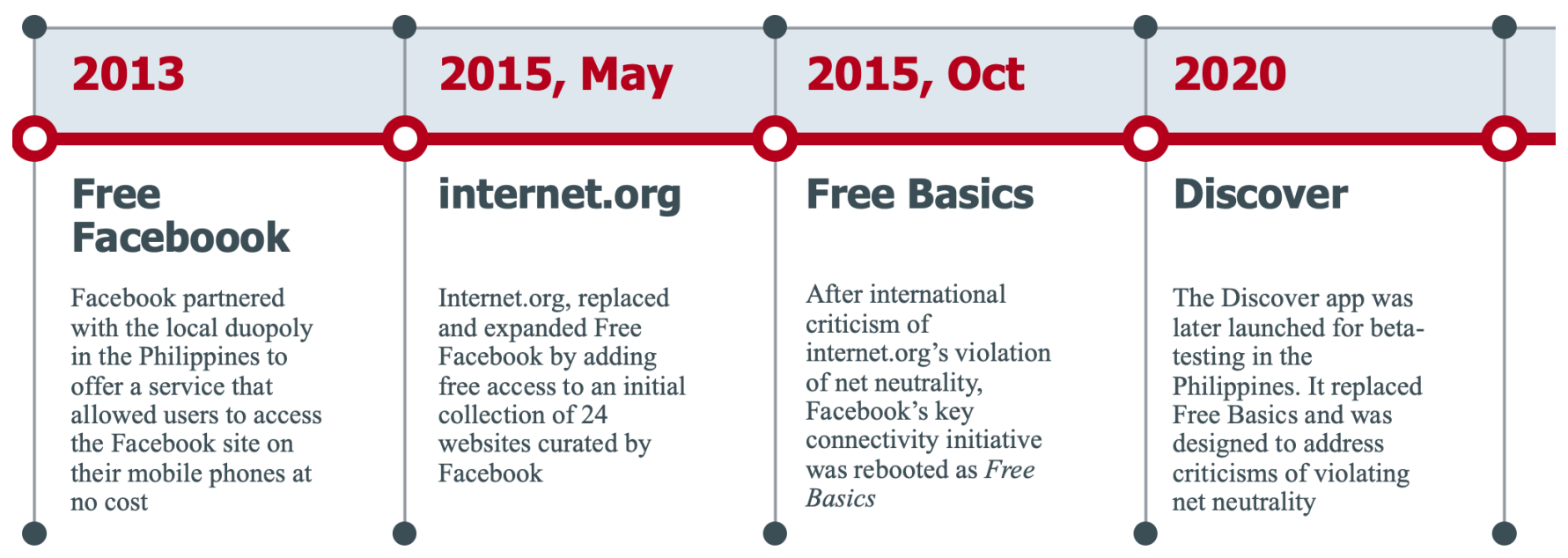

Figure 1: Timeline of Facebook Connectivity initiatives in the Philippines.

either as a philanthropic endeavor, a provider of universal benefits, or a first-step fix to social issues. Several scholars reflect the same frames in their findings, often invoking free internet access as a solution to digital divides. Yim et al. [79] claim that Free Basics facilitates community development by promoting different kinds of social bonds. Layton and Elaluf-Calderwood argue that users "are clearly worse off when free data is prohibited or restricted," [38]. For example, they posit that health issues could be addressed through information freely disseminated through Free Basics. Using an economic model, Joe-Wong et al. [34] predict that cost-sensitive users would benefit from Free Basics relative to other stakeholders.

On the other hand, Best [9] argues that Free Basics as a "Facebook on-ramp presents significant privacy concerns," violates network neutrality principles, and stifles innovation. Bonilla et al. [11] evaluate the app in six countries to argue that Free Basics violates net neutrality principles. They conclude that "the data and content limitations built into Free Basics are largely artificial," and "are put in place in order to increase Facebook's ability to collect and profit from user data" [11]. Amidst more wholesale endorsements and critiques of Free Basics, some researchers are cautiously optimistic about the potential benefits of this access configuration for development even as they point to its technical constraints [62, 63, 67]. Taking into account these constraints and critiques of Free Basics, designers have sought alternative methods for low-cost internet provision $[21,56]$.

Other studies take the perspectives of users who express various degrees of dissatisfaction. Romanosky and Chetty's [58] engagements with both users and nonusers showed that while Free Basics shaped internet usage, participants were confused about the extent to which the arrangement was free. Gebhart [27], on the other hand, found that users in Ghana interpreted Free Basics as a promotion for the telecom company but preferred it less than other types of data promotions. In South Africa, Phokeer et al. [54] found that users preferred to pay for the full functionality of applications over using Free Basics, which lacked pictures and videos. This is echoed by Zamora's [80] findings in Brazil and India where users do not settle for less just because "something is better than nothing." Finally,
Uy-Tioco [75] situates Free Basics within the Philippines' socioeconomic class divisions. She argues that low-income Filipinos are able to participate in some capacity on the internet through applications like Free Basics, yet the constrained quality of their access reproduces social stratifications.

While scholars have studied Free Basics, as we have summarized in our review, its successor Discover remains unstudied. Facebook claims that the design of Discover has improved upon and addressed the criticisms we have outlined $[10,18,81]$. Our work, in response, brings the lens of document theory to analyze such claims. Our approach frames internet access via Discover as a specific configuration of costs and benefits that situate users in a particular economic and political relationship.

\section{METHODS}

\subsection{Document Theory in HCI}

Our analysis of Facebook Discover utilizes document theory, following the way the framework has been applied to HCI. Drawing from the field of documentation studies, Olsen et al. [48] propose a document model for analyzing sociotechnical systems. The model is grounded in the premise that documents mediate and govern social relations [14, 25]. Documents, broadly construed, are objects that signify something $[20,40]$ and are viewed as "products of [their] context of creation and, furthermore, as active agents in this context" [68]. Studying documents and the documentation process that creates them enable a system's explicit and implicit goals to be made visible alongside their underlying logics [48]. Olgado et al. [47] further developed the model and applied it to HCI research, showing document theory's utility in bringing political economy into our understanding of computing.

In this study, we take as our object of analysis the set of all websites viewed through the Discover app. Our study follows the framework laid out by Olsen et al. [48] and operationalized by Olgado et al. [47] to treat these sites as documents for analysis. This document model, shown in Figure 2, illustrates how this theory is divided into seven components that describe documentation 
processes and documents holistically. The documentation process requires agents as creators, a set of tools to be utilized, and a mechanism to utilize such tools to form the resulting document. The document model further points out that agents have motivations that drive them to produce documents. The means for this documentation processes is a system of input and output mechanisms that shape the modality of the document's use and visibility. The resulting document is shaped by the interrelationship between the agents, means, and modes. We are therefore analyzing the agents, means, and modes that result into the form of websites accessed through the Discover app.

The last three components of the model - mental configuration, social connection, and physical construction - are outside the scope of this study. These components comprise the "complementary analysis" that enable the understanding of documents and documentation processes in situ [48]. Studying them entails a different set of methodologies which we hope future work will take on.

Document theory allows us to investigate the political economy of computing and access arrangements via the artefactual document [47]. While this initial study of a recently launched app has limitations given its nature and timing, we argue for the urgency of the work precisely because interventions are needed early on Document theory provides a framework and index to do this. In our study, we begin such work by employing the first half of the document model.

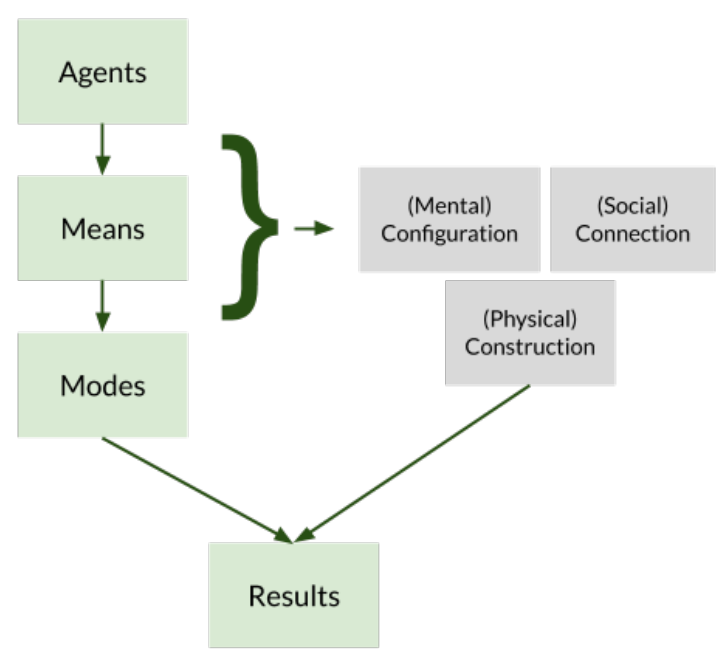

Figure 2: Schematic of the document model, adapted by [47] from [48], showing how agents, through specific means and modes, arrive at results in the documentation process.

\subsection{Research Questions}

Adopting the model's line of inquiry and the study's stated scope and limitations, we sought to answer the following questions and present our findings accordingly.
(1) Agent: Who is involved in rendering and organizing the websites as they are viewed on Discover?

(2) Means: What is used to render the websites?

(3) Modes: How are websites organized and made visible on Discover?

(4) Result: How do the rendered websites look on Discover?

\subsection{Data Sampling, Collection, and Analysis}

To respond to the research questions laid out above, we analyzed websites as they appeared on Discover in the Philippines. As Discover presents websites based on popularity and by category, we selected the most popular website in each of the 12 categories to study. We also included the top 10 most popular websites overall. As some of these sites overlapped, our total sample included 19 sites, summarized in Table 1.

Research collaborators based in the Philippines accessed the selected websites via Discover on Android mobile devices connected to Smart and Globe networks. We had one researcher from the De La Salle University's Center for Complexity and Emerging Technologies (COMET) Laboratory do a preliminary survey in July 2020. Two research assistants from the University of the Philippines School of Library and Information Studies (UP SLIS) then accomplished the rest of the data gathering in August of the same year. The researchers were first time users of Discover. Researchers verified that the Discover homepage and a sample of websites appeared the same on the Smart carrier as they did on Globe.

For each site in the sample, the researchers attempted to accomplish the main purpose of the site (e.g. buy something, gain information, make a bank transaction, etc.). The researchers documented barriers to their attempts to complete a task, for example, when search queries failed, or when captcha images were blocked by Discover's stripping of images. Screenshots of the landing page of each of these sites were also collected for analysis. Attempts to accomplish tasks on websites in Discover resulted in a coding of the site as functional, semi-functional, or non-functional (see Figure 3).

Screenshots of the landing page of each of these sites were also collected for analysis. We compiled descriptive statistics to quantify the extent to which websites' content was removed by Discover. We did this by calculating the area of the landing screen of each app that was occupied by gray boxes which replaced images and videos removed by Discover (see Figure 6). In addition to this spatial measure, we counted the number of missing images relative to other content on the page.

Additionally, we reviewed the press releases and EULAs (enduser license agreement) surrounding the launch of Discover and its predecessor, Free Basics. These contributed to our understanding of the documentation process, particularly the agents and means involved in the rendering of the websites on Discover. To provide points of comparison, we also reviewed screenshots and reports about Free Basics as it appeared in the Philippines in 2017 from an open-data research report [11].

\section{FINDINGS}

In the sections that follow, we use the document model described above to discuss the agent, means, modes, and result of the 19 websites we sampled on Discover. 
Table 1: Websites Included in Sample

\begin{tabular}{ll}
\hline Category & Website \\
\hline Coronavirus & World Health Organization (WHO) \\
Business and Finance & Bank of the Philippine Islands (BPI) \\
Education & YouTube \\
Government & Department of Education (DepEd) \\
Health & Healthline \\
Home \& Lifestyle & Food Panda \\
Jobs & Jobstreet \\
News & Yahoo! \\
People \& Society & Jehovah's Witness (JW) \\
Shopping & Shoppee \\
Social \& Apps & Facebook \\
Sports & Sports Interactive Philippines (SPIN Ph) \\
Popular & Kissasian \\
Popular & Instagram \\
Popular & Netflix \\
Popular & Wikipedia \\
Popular & Twitter \\
Popular & Google \\
Popular & Roblox \\
\hline
\end{tabular}

\subsection{Agents: Who is involved in rendering and organizing the websites as they are viewed on Discover?}

Documents are produced by actors with specific motivations. These motivations shape the nature of the document and drive the process of documentation [48]. Documents can be authored by several actors and so the documentation process can be influenced by overlapping and at times competing motivations [47]. Identification of actors can also occur at several levels, from the broader level of organizations and entities to the micro-level of engineers and clerical workers. Here, our focus is broadly on the level of entities and organizations. By analyzing the agents at play in rendering and organizing the websites as they appear on Discover, we identify actors involved in this documentation process, their stipulated motivations, and the dynamics/relations between them. This section sketches out the agents involved and foreshadows further analysis that will be detailed in the following sections.

Two agents are most noticeably at play in rendering the website on Discover: the website creator, who designs the site; and Facebook, who renders the site on its Discover app. While the website creators design sites to look a particular way, the end results will be rendered by Facebook to be "data efficient so that they can be accessed without data charges" [18]. Although a user will experience only a single document, the document they are viewing has been effectively co-authored. Our analysis of the means will identify how this co-authorship functions and our analysis of the result will show how the final document is formed differently than what was intended by the site creator.

Mobile carriers are also involved in this documentation process. The telco duopoly in the Philippines partnered with Facebook to offer Discover in the Philippines, stating that they "continue to share with Facebook the common goal of expanding the digital lifestyle and make it more inclusive" [60]. Under this articulated motivation is the telcos' strategy to "stimulate millions of Filipinos and introduce them to the internet through Facebook... [and find ways to] get them pay for it and use other services as well" [45]. In line with these motivations, the telcos have influence over how the document appears on Discover as our analysis of the means will show.

Discover also organizes websites into categories based on popularity as measured by SimilarWeb, a third-party web analytics company that offers "innovative market intelligence solutions to empower businesses to make better decisions" [66]. Our discussion of the modes will delve into these categorizations and how they influence the shape of the internet as presented by Facebook.

In mapping out the agents at play, the dominant narrative of Facebook as the only agent in this documentation process is questioned, as the other agents are made visible. Facebook enters a preexisting arrangement of players with their own set of motivations and strategies, including the telecom dupoly's market expansion goals through extensive use of microtransactions. The articulated motivations of these agents, such as Facebook's purported philanthropic motives, may not necessarily be aligned with the logics and assumptions that are made visible through document theory. Our findings and analysis of the means and the modes will show such tensions, while the result section will analyze the inconsistent outcomes of these co-authored documentation processes.

\subsection{Means: What is used to render the websites?}

Agents use instruments to create the document: these are the means that enable documentation to happen. The process of documentation, in this case the rendering of the website on Discover, necessitates a system of input and output technologies and mechanisms [48]. Analyzing these instruments is not only a technical exercise; it can also make visible underlying logics and politics of the system and question articulated motivations of the agents [47].

When a user in the Philippines searches for "free basics" on their mobile device, they are redirected to the Discover homepage. Discover can also be downloaded directly from the Google Play store. With Discover, a user can browse the internet with a $10 \mathrm{MB}$ cap of free data per day. Figure 3 shows the Discover homepage, which features a built-in Google search bar as well as a listing of predetermined popular sites based on SimilarWeb's metrics. A user could opt to search for any site, using the search bar or by accessing a search engine of their choice.

The premise of Discover is that browsing can be made free through the data-efficient version of sites rendered on the app. Data-efficiency is achieved through not supporting video, audio, file transfer services, streaming, Flash, and Applets. Facebook's description of the support for images is ambiguous and indicates that the mobile operator has a role in determining the extent to which images may display when browsing via Discover. Figure 4 illustrates the way this is achieved: browsing through Discover is routed through a proxy which allows for the carrier to recognize that browsing is free. Facebook notes that this also allows website developers to measure the traffic they are reaching through Discover. Where unsupported content would have appeared, a gray 
Table 2: Comparison of Free Basics and Discover

\begin{tabular}{ll}
\hline Free Basics & Discover \\
\hline Limited available sites for free & No restrictions on sites that can be visited \\
\hline No data limit & 10 MB daily free data limit \\
\hline $\begin{array}{l}\text { (Modified) websites submitted by creator to Facebook } \\
\text { for approval and inclusion }\end{array}$ & $\begin{array}{l}\text { Sites automatically modified by Facebook, site creator } \\
\text { not involved }\end{array}$ \\
\hline $\begin{array}{l}\text { Lower quality images, removed JavaScript (so most ads } \\
\text { removed), and many links cannot be followed without } \\
\text { paying [63] }\end{array}$ & $\begin{array}{l}\text { "Video, audio, or certain other data-intensive types of } \\
\text { trafich as file transfer services" are not supported. } \\
\text { may be not supported or lower quality, depending on } \\
\text { carrier. JavaScript is supported. Responses that are 1MB } \\
\text { or greater will not pass through to the client" [18]. }\end{array}$ \\
\hline Speed throttled & Not tested \\
\hline
\end{tabular}

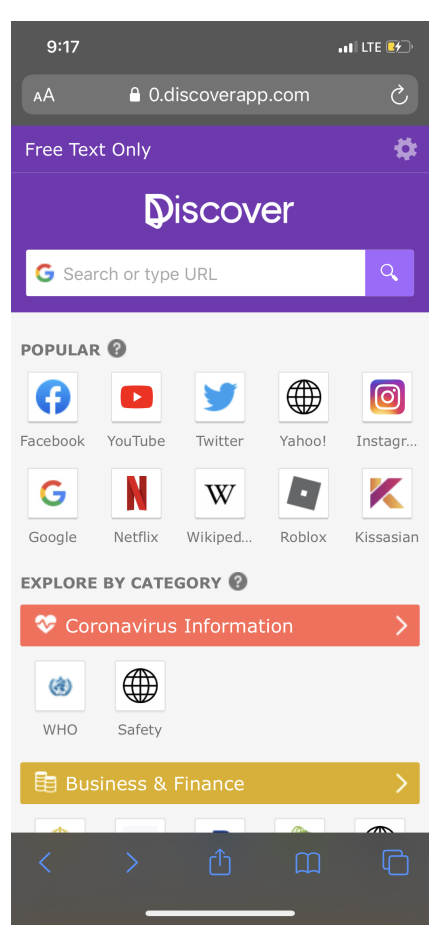

Figure 3: Screenshot of the homepage of Discover, featuring a Google search bar and shortcuts to predetermined popular sites

box with the text "Use data to see photos" appears instead (see Figure 7).

The model of Discover, which dynamically removes data-intensive content from any site on the internet, stands in contrast to the model of its predecessor, Free Basics. Table 2 summarizes the differences between the means of Discover and Free Basics. Free Basics offered a limited set of websites that users could browse for free, with no restrictions on data or time. In order to have one's site included on
Free Basics, a developer had to ensure the site followed the dataefficient technical requirements set by Facebook and then submit the site to Facebook for approval. According to prior researchers, Facebook responded within two weeks for their various submissions, and did not make any comments on the content of the site submitted to be included [63].

By contrasting the means of the documentation process through which websites are rendered on Discover with the model of Free Basics, we can see how Facebook attempts to address prior criticisms. The means however still operate within logics of access through constraints. While Facebook may seem to appease calls for net neutrality, our analysis of the result will show that this may not be the case due to uneven redaction of images based on the discretion of the telcos.

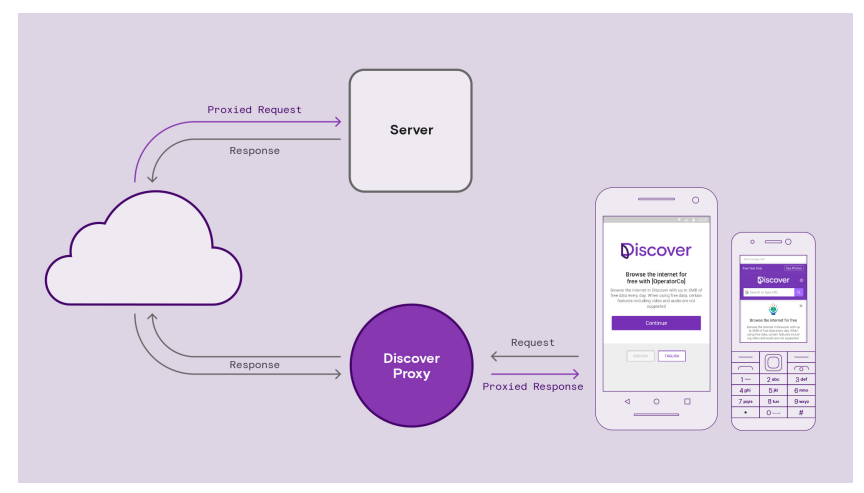

Figure 4: Facebook explains the use of proxies in Discover. Image by Facebook Connectivity, via "Discover Technical Information" (https://connectivity.fb.com/discover-technicalinformation/).

\subsection{Modes: How are websites organized and made visible on Discover?}

Mode refers to the dynamics between the agents and how these agents utilize the means [47]. In the case of Discover, this points to 
the control of how sites are presented and how they are organized. Unlike Free Basics where sites that can be visited were limited, Discover enables users to access the entirety of the internet. While this addresses the walled-garden aspect of net neutrality, a closer analysis of the mode shows how Facebook still effectively wields control over: how the internet is presented, who is represented on the internet, and what portion of the internet becomes visible.

4.3.1 Artificiality of Categorization. While all of the internet is technically available on Discover, our analysis of the platform found a total of 72 sites that are prominently made visible on the application. They are listed and sorted under 13 categories (see Table 1). Expanding these categories reveals 21 subcategories containing a total of 272 websites.

As Bowker and Star have shown, it matters who makes the categories [13]. The categories on Discover strongly resemble those used by SimilarWeb, whose popularity rankings are used by Discover. SimilarWeb categorizes websites using content tags, similarity results, and "a learning set of millions of websites that have verified category assignments" [65]. While the featuring of sites is primarily ascribed to SimilarWeb, Facebook asserts they may directly feature sites on the Discover homepage in the case of "health and safety resources," as demonstrated by the Coronavirus category that appears at the top of the homepage. Facebook also exercises agency in excluding certain categories of content regardless of their popularity as in the case of pornography and gambling [24]. For example, though SimilarWeb ranks Pornhub as the 5th most popular website in the Philippines, it is not listed on Discover.

SimilarWeb claims that their engine (and interns) can "accurately classify an unknown website" [65]. Accuracy lends itself to the idea of an uncontroversial, common truth. However our findings show that these categorizations lead to some unexpected results even for very well known websites. For example, the decision to include Facebook, Twitter, and Instagram under the category Education is contestable. Under the category of People \& Society, dating sites such as Filipino Cupid are placed alongside Bible Gateway, a searchable online bible. When an app commonly used for hookups like Tinder is placed together with the website of Jehovah's Witness, their juxtaposition makes visible the artificiality of the categorization and the agency of the actors involved in making such classifications.

4.3.2 Valorization through Ranking. Facebook presents popularity as a neutral way to categorize and choose websites to make visible on Discover. For each subcategory no more than ten websites are included and their selection and arrangement are based on SimilarWeb's proprietary popularity metrics. This categorized and ranked listing functions as a popularity-based recommendation system. Research has shown [78] that such systems heavily influence user behavior through selective exposure that further strengthens bias towards what is already popular. Only making popular items dominantly visible does not lead to discovery of new items and thus will ignore diverse user tastes [1]. This creates a self-perpetuating cycle of what is included and excluded. This popularity-driven process is value-laden, as it leaves little space and sets a high barrier of entry for new players to be visible [64]. At the same time, we found that Discover lists malicious sites such as Tsyndicate.com, a site to which users who have devices infected with malware are redirected to view intrusive advertisements that can collect data and can further spread computer viruses. Tsyndicate.com's popularity is driven only by the frequency with which users are unintentionally redirected to the site.

This valorization of some points of view and silencing of others [13] through market categories and popularity standards is further illustrated by the geopolitical makeup of the internet as presented by Discover. Figure 5 shows that nearly half of the sites presented on Discover are owned by United States-based entities. On the other hand, sites owned by Philippine-based entities make up only $21.7 \%$ of what is shown on Discover. An entire $8.8 \%$ of the sites are of undeterminable origin, and many of those sites are of questionable legality, as they host free access to copyrighted content. As classifications shape worldviews and social interactions [13], Facebook's modal decisions and choice to pass such decisions to third party agents on what is made visible and how they are made visible are geopolitically value-laden.

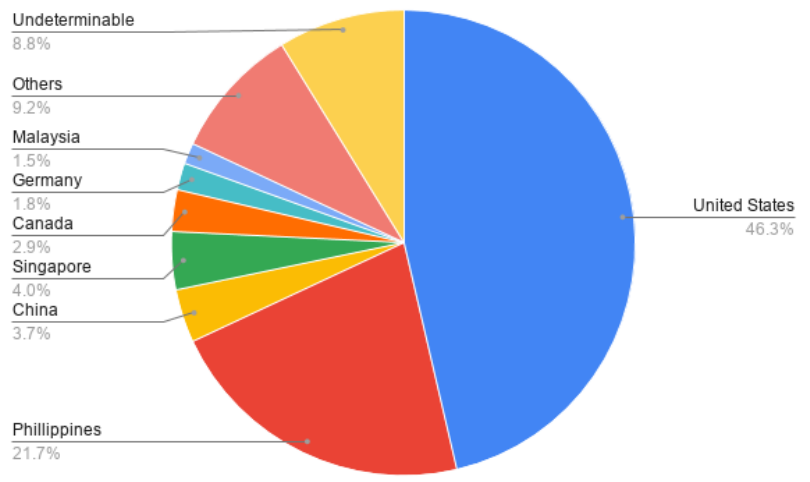

Figure 5: Country of ownership of the 272 websites that are presented on Discover

This exclusionary mode of categorization and ranking, as we have shown, enables the various agents involved through Discover to shape the perceived classified functions of the internet, perpetuate the popular (even if it is malware), and assert the primacy of the US in constituting the internet and informational capitalism.

\subsection{Result: How do the rendered websites look on Discover?}

We are interested in how these negotiating agents, constraining means, and categorizing modes shape the result of this documentation process - the websites as they are rendered on Discover. While Facebook claims that all websites are treated equally on their platform [81], it seems this is not the case in practice. Our findings show that the extent of redaction and consequently the level of functionality differs greatly across websites.

4.4.1 Redaction and Unequal Rendering. We use the term redaction here to refer to the spatial representation of content that has been hidden in the rendering of sites through Discover. Facebook consistently removes all videos, audio, and other types of media 
Table 3: Functionality of sites in our sample

\begin{tabular}{c|c|c}
\hline Functional & Semi-Functional & Non-Functional \\
\hline Department of Education & Bank of the Philippine Islands & Food Panda \\
Facebook & Instagram & Netflix \\
Google & Kissasian & Roblox \\
Healthline & Sports Interactive Philippines & Shopee \\
Jehovah's Witness & Yahoo! & Twitter \\
Jobstreet & Youtube & \\
World Health Organization & & \\
\hline
\end{tabular}

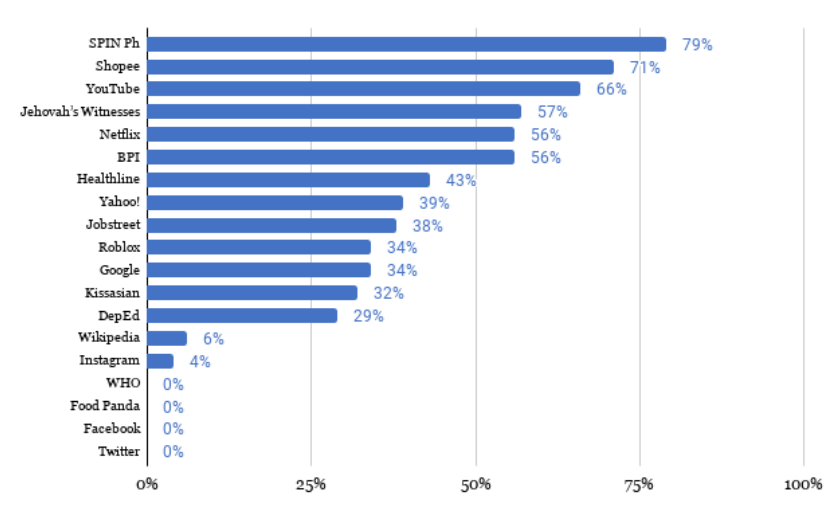

Figure 6: Percentage of redacted space on the landing screen

mentioned in the means section, but the discretion that is built into the way Discover operates leaves room for carriers to violate net neutrality by only showing images on certain sites. On both Globe and Smart, images on Facebook and Instagram appeared, while most or all images were redacted from every other site we encountered. On a few sites, images appeared only for advertisements.

The functionality of sites relies on images to different degrees. However, functionality is not considered in redaction decisions, nor is it considered in the selection of featured sites. Figure 6 shows the percentage of space redacted on the landing screen of each of the sites in our sample. This space-based analysis illustrates the visual experience of attempting to access the internet via Discover. One is met with an array of gray boxes that cover more than a third of the screen space in 11 out of 19 sites and more than half the space in 6 out of 19 sites in our sample. The uneven redaction of sites creates an unequal rendering of the internet, where Facebook and Instagram have their features nearly intact, while other sites become broken or difficult to use, as we will discuss in the next section.

4.4.2 Redaction and Degrees of Functionality. Table 3 summarizes the degrees of functionality of the websites we analyzed. On a few sites such as Wikipedia, we found the experience was comparable to that of browsing the site outside of Discover. Redaction of images sometimes affected the ability to glean certain types of information, but the site was navigable and we could get a good deal of information from the site. On the other extreme, we found several sites that were non-functional. Some of these sites relied heavily on images, including for navigation. Shopee is an example of this, where we could not navigate the site and it was impossible for us to accomplish the task of shopping or making a purchase. Many of the sites we encountered were semi-functional-it was possible for us to accomplish some tasks, but key functions of the site could not be completed through Discover. For example, on YouTube, the videos could not be watched, but the search function still worked and we could get information about the title and description of the video. On the website of the Bank of the Philippine Islands, we could not conduct transactions, but information about branch hours was still obtainable.

Functionality is primarily affected by the redaction of images. For example, captcha mechanisms that require users to select or identify images to prove that they are human did not work (see Figure 7, center screenshot for an example). Because of this, creating accounts or recovering passwords were virtually disabled. Besides image redaction, other underlying systems were also inconsistently disabled, leading to other dis/non-functionalities. For example, the search function worked on Youtube and other sites but not on the Jehovah's Witness website. When attempting to log in on Roblox we consistently faced errors, while on sites such as Facebook we did not encounter login issues. Messaging worked on Facebook but not on Instagram. On the food delivery app Food Panda, geolocation services were disabled, making the site nonfunctional.

Our review of the results of this documentation process shows how uneven redactions lead to varying levels of functionality, presenting a skewed internet that favors some and leaves others behind. The modal decisions of categorization and ranking by SimilarWeb, which Facebook employ, do not align with the redaction decisions of Facebook and the telcos. Here we see how the differing motivations and logics of these various agents lead to a configuration of access that delivers a constrained version of the internet that, we will argue, situates the Philippines in perpetual geopolitical precarity.

\section{DISCUSSION}

Following our findings, we begin our discussion by proposing that the combination of Facebook and the telcos' control of categorization and redaction amounts to form moderation. Our discussion then turns to how Facebook Connectivity is embedded in expanding market colonization. Finally, we consider our findings alongside a history of market co-option of community economic strategies of precarious people in the Philippines. 

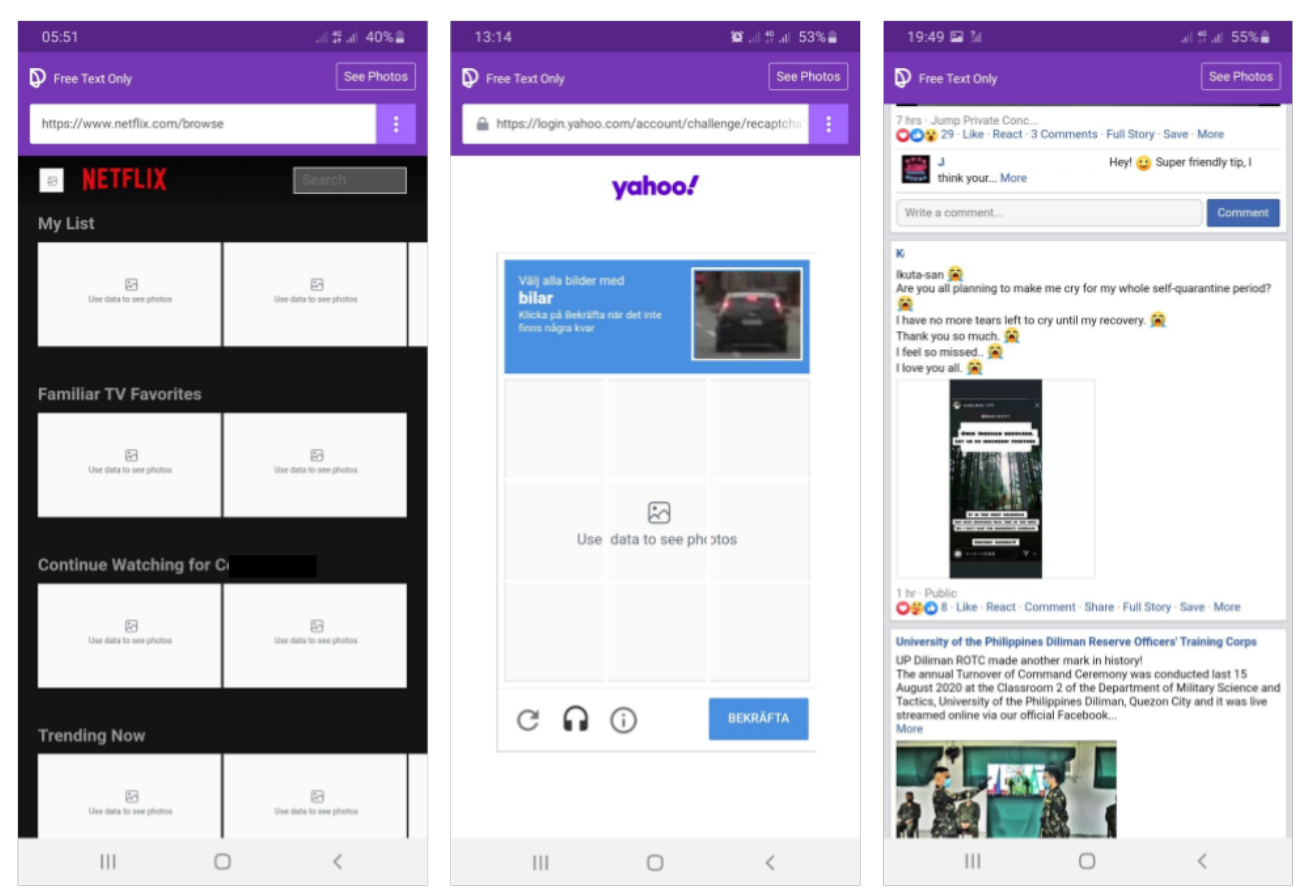

Figure 7: Screenshots of three sites as viewed through Discover. Left: Netflix was virtually unusable since even the names of shows were contained in redacted images. Center: Yahoo! was very glitchy and for unknown reasons showed up in Swedish. The user is unable to complete the captcha without paying for data to see the images. Right: Facebook still shows up with images included because of the discretion of telecom companies in the Philippines.

\subsection{Form Moderation through Categorization and Redaction}

The meaning and functionality of a document is shaped by its content, context, and form [52]. Form, in document and archival studies, refers to the appearance and arrangement of content. The form defines and contains boundaries, and thereby asserts relationships between entities. These boundaries and relationships shape meaning and enable utility of the document. Applied to this study, form refers to both how websites are organized and how webpages are rendered on Discover.

Because form and content are co-constituted, the content of a particular document takes a different meaning when the document's form is restructured. And so while studies have focused on how content moderation online "shapes social norms and creates consequences for public discourse, cultural production, and the fabric of society," [28] we argue that analytical focus should also be directed towards the politics and impact of form moderation. In the case of Discover, Facebook serves as a "custodian of the internet" [28] by also engaging in form moderation through categorization and redaction of web pages under the guise of free connectivity.

While the entirety of the internet can be accessed through Discover, the app still asserts a jussive force that is invisibly exclusionary [12]. This is seen in the way Facebook and SimilarWeb as agents operate modally through market-driven appraisal and arrangement. The acts of categorization and ranking create and assert genres and micro-genres in service of capital, presented as being "ostensibly tailored to users but actually designed... to keep users partly satisfied and partly redirected to corporate interests" [69]. The indices that these agents and modalities create function as a recommender system that governs and shapes the audience preference it purports to reflect [7]. The visibility and ease of access to the popular contribute to the self-perpetuating cycle of invisible exclusions and the myth of choice. The indices of Discover are as influential as the content they carry.

Facebook also moderates form on the discrete level of how web pages, as results of documentation, are rendered on Discover. This form moderation materializes primarily as redactions. Redaction differs from content moderation that hides or removes content due to issues of privacy, security, or appropriateness. Redaction on Discover, as form moderation, functions in two ways. In our analysis of the means, the redaction of objects on web pages is claimed by Facebook as a technical requirement to deliver free internet. Redaction is a "black box process that takes place using guidelines we cannot discern directly; our access is limited to the end product, the redacted document" [39]. And so, through document theory we instead make visible the logic and assumptions of that redacted document. Our findings point out that redaction on Discover is a mechanism of the market that fully renders some sites while obscuring others through profit-motivated constraints. 


\subsection{Entrenched market colonization}

Facebook Connectivity carries market expansionist motives as seen when they described their initiatives as a "gateway drug" or an "on-ramp" that leads to further consumption [30]. Our findings on Discover reveal an easy-to-obtain taste of the internet that encourages and demands spending to fully participate in contemporary informational capitalism. Nothias [46] draws an instructive parallel by comparing Facebook's free-sample strategy with Nestlé's marketing practices in the 1970s for baby formula. This strategy provided free samples to create a need where there was none before and to build up a dependency on a new product conceived to be good.

Facebook works to colonize an untapped precarious market with Discover by giving free, albeit redacted, samples of the internet. We found redaction to be a profit-motivated constraint that both frustrates and teases. Redactions disrupt meaning creation and titillate deductive imagination as the "desire to uncover the invisible" is conjured [44]. To satisfy this desire or breach this restriction, the market demands payment. This situates the Philippines as a consumer, one that is always bereft as the very structural inequality that access to the Internet frequently claims to ameliorate is reproduced.

The constraints we found through our document analysis illustrate that Uy-Tioco's [75] argument still stands: that access provided by Facebook Connectivity initiatives perpetuate class divides, cultivate neoliberal subjects, and make cheap labor available to global actors. While acknowledging the benefits that even low-quality access can provide for low-income people toward survival and coping, she points out that "these products and services are tailor-made for the precarious; their very existence is thus predicated on the existence and persistence of deep inequalities in economic and social life" [75].

Although Discover provides extremely limited benefits of internet connection for free, it nonetheless enforces uneven access, for it continues to be predicated on the precarity of its users.

\subsection{The Logics of Sachet Marketing}

The narratives surrounding Facebook's Connectivity initiatives frame Facebook as a philanthropic agent that answers a self-declared moral call to improve "the social infrastructure that is still nascent in many developing countries" [82]. Our analysis however shows that rather than providing internet access to an empty and barren land, Facebook enters preexisting arrangements with which it must negotiate and contend. In the case of Discover in the Philippines, Facebook has to negotiate with an existing telecommunications duopoly and their long-established logic of sachet marketing [6] and their flawed version of tingi ${ }^{3}$ economics [41].

Sachet marketing is a strategy to increase market penetration by "redesigning, packaging, and selling a product or service in a smaller form, made available at a more affordable price" [6]. This leads cashflow-constrained consumers to make frequent purchases as opposed to more cost-efficient bulk alternatives. Sachet marketing

\footnotetext{
${ }^{3}$ The practice of selling and buying goods on a per use basis, in incremental amounts less than the smallest market retail packaging. This includes for example selling and buying a spoonful of sugar for a serving of coffee or a cup of kerosene for a night's worth of lamp fuel. Community members will usually bring their own vessel and repackaging is done on a point-of-sale basis like refilling stations.
}

is a co-opted corporate form of a community retailing service established during the Spanish colonial period in the Philippines [19]. Sari-sari stores (a store of assortments) are informal small owneroperated micro-retail outfits ${ }^{4}$ that serve the working poor through ting $i$ economics: accessible, affordable, and flexible payment arrangements that do not pass the cost of margins onto buyers [36]. As Matejowsky [41] argues, sari-sari stores "have emerged as the defacto food pantries of neighborhoods," shaping community life for generations. Corporations looked at sari-sari stores and the tingi system and drew from them both consumer needs for and behavior towards micro-sales. While sachet marketing's delivery of products seem to be similar to that of the tingi system, the former operates within consumerist logic while the latter is communitybased. Corporate sachet marketing has been effective in co-opting tingi culture while setting aside its community aspect ${ }^{5}$.

The duopoly of telecommunication companies in the Philippines and Facebook have embraced sachet marketing in their rollout and delivery of Discover. While these agents have purported to deliver free access to users, their actions are shown to be driven by their motivation to expand their markets to precarious users. Our analysis of means illustrates how Discover redesigns, packages, and sells internet access in smaller forms like digital sachets. The last digital frontier market is reached through these digital sachets that perpetuate precarity. However, the history of sachets as being co-opted from the sari-sari store reminds us that other possibilities for configuring access are possible, such as one that could produce a neighborhood internet pantry that lives up to the promise of accessibility, affordability, and flexibility.

\section{CONCLUSION}

In this paper, we have used document theory to systematically analyze Facebook Connectivity's recently-launched internet browsing application, Discover, in the Philippines. We found that Discover is constituted by a collection of redacted documents that are produced by negotiating agents, constraining means, and categorizing modes that operate within and through market logic. We argue that this profit-driven logic of redaction and form moderation further extracts from precarious consumers by colonizing new markets, rather than ameliorating structural inequality. This configuration of purposefully limited access then situates the Philippines as a consumer that is always craving for more, enabling Facebook and other agents to turn the Philippines into their market, testbed, and backroom. Rather than viewing the forays of large tech companies into the Global South as philanthropic acts, we argue that these ventures should be regulated. We direct attention to the particular need for the consideration of transnational geopolitics in regulating Facebook and other multinational tech companies. At a smaller scale, we urge engineers and technologists implicated in technology companies' colonizing actions to mobilize in solidarity with those affected by the products they design and create, and hold

\footnotetext{
${ }^{4}$ Sari-sari store operators buy wholesale products from supermarkets and sell them as per-need-micro-units prorated according to the suggested retail price. The operator earns from the wholesale savings through purchasing wholesale rather than from putting margins passed on to buyers.

${ }^{5}$ Over 163 million pieces of sachets are sold in the Philippines every day, proof of the market hold of corporations, the weakening of community provision, and the growing threat of consumer-driven pollution.
} 
their employers accountable for the ethical standards they claim to follow [33].

Though Discover is still in its initial roll-out stages, Dourish et. al. [22] remind us that the marginalized communities for whom it is deployed face a continuous state of iteration that causes harm and is part of a longer engagement across inequality and uneven power. The launch of Discover, though it may still be in beta, is part of a longer relationship between Facebook and precarious populations in the Philippines. The marketing of Discover as a charitable solution enforces the precarity of low-income users by creating the image that their problems are being solved by entities such as Facebook. If Discover is seen as a step in the right direction over Free Basics, the need for critique is seemingly diminished.

Future work can take on other parts of the document theory model, which were out of the scope of this study. By studying how different agents understand the documentation process through configuration, connection, and construction, [48] future work could add robustness to the analysis conducted here. Doing a complementary analysis of documents and documentation processes necessitates methodologies beyond what we employed here. This includes, for example, analyzing (1) the mental configuration of Discover users through cognitive task analysis, (2) the social connection between Filipinos in diaspora using digital ethnomethodology, and (3) physical construction via comparative material assessments between Free Basics and Discover. Additionally, engaging with users of Discover in the Philippines would further provide valuable insights as to how the result of the documentation process studied here is interpreted and valued by those who are its purported beneficiaries.

Like all kinds of research, ICT4D and HCI work are deeply invested in geopolitical relationships. Through document theory, we join works that bring political economy into frame in social computing research. Document theory provides a set of tools that moves research past binaries of good and bad in computing arrangements, enabling a more specific accounting for what has been produced by specific sociotechnical configurations. In centering our study in the Philippines we argue for the country's importance as a nexus of global informational capitalism with its own set of actors and entanglements that speak of the enmeshed global networks of labor and capital. The history and context of the Philippines inspire our critiques against sachet marketing. Likewise, an understanding of the history and culture of the Philippines inspires our vision for alternatives, including community-based provisions of goods as exemplified by sari-sari stores and their tingi economics.

\section{ACKNOWLEDGMENTS}

We thank our undergraduate research assistants, Beatrice Bernardin Tan and Ces Archae Buenavista, from the University of the Philippines School of Library and Information Studies. We also extend our appreciation to Unisse Chua and Briane Samson from the De La Salle University's Center for Complexity and Emerging Technologies (COMET) Laboratory for their support.

\section{REFERENCES}

[1] Himan Abdollahpouri. 2019. Popularity Bias in Ranking and Recommendation. In Proceedings of the 2019 AAAI/ACM Conference on AI, Ethics, and Society. ACM, Honolulu HI USA, 529-530. https://doi.org/10.1145/3306618.3314309
[2] Neil Angelo S. Abreo, Kirsten F. Thompson, Glio Florgiley P. Arabejo, and Michael Dann A. Superio. 2019. Social media as a novel source of data on the impact of marine litter on megafauna: The Philippines as a case study. Marine Pollution Bulletin 140 (March 2019), 51-59. https://doi.org/10.1016/j.marpolbul.2019.01.030

[3] Erwin A Alampay, Liane P Alampay, and Khane S Raza. 2013. The Impact of Cybercafés on the Connectedness of Children Left Behind by Overseas Filipino Workers. Technical Report. Technology \& Social Change Group at the University of Washington Information School, Seattle, WA. http://hdl.handle.net/1773/23891

[4] Davey Alba. 2018. How Duterte Used Facebook To Fuel The Philippine Drug War. https://www.buzzfeednews.com/article/daveyalba/facebook-philippinesdutertes-drug-war Library Catalog: www.buzzfeednews.com.

[5] Aloha May Hufana Ambe, Margot F Brereton, and Markus Rittenbruch. 2016. Vendors' Perspectives of Coordination in the Information Technology Offshore Outsourcing Industry: An Exploratory Study from the Philippines. In Proceedings of the 19th ACM Conference on Computer-Supported Cooperative Work \& Social Computing - CSCW' '16. ACM Press, San Francisco, California, USA, 318-333. https://doi.org/10.1145/2818048.2819991

[6] Rodolfo Ang and Joseph Sy-Changco. 2007. The phenomenon of sachet marketing: Lessons to be learned from the Philippines. In 2007 AMA Educators' Proceedings Enhancing Knowledge Development in Marketing. American Marketing Association, Washington, DC, 5-15.

[7] Sarah Arnold. 2016. Netflix and the myth of choice/participation/autonomy. In The Netflix effect: Technology and entertainment in the 21st century (1st ed.). Bloomsbury Publishing Inc, New York, NY, 49-62.

[8] Jessie S. Barrot. 2016. Using Facebook-based e-portfolio in ESL writing classrooms: impact and challenges. Language, Culture and Curriculum 29, 3 (Sept. 2016), 286301. https://doi.org/10.1080/07908318.2016.1143481

[9] Michael L. Best. 2014. The internet that Facebook built. Commun. ACM 57, 12 (Nov. 2014), 21-23. https://doi.org/10.1145/2676857

[10] Simon Blackstein, Itay Duvdevani, and Scott Renfro. 2020. Discover's secure web-based proxy service. https://engineering.fb.com/connectivity/discover/ Library Catalog: engineering.fb.com Section: Connectivity.

[11] Monica Bonilla, Kofi Yeboah, Njeri Wangari Wanjohi, Giovanna Salazar, Faisal Kapadia, Mahnoor Jalil, and Mong Palatino. 2017. FreeBasicsinRealLife_FINALfuly27.pdf. Technical Report. Global Voices, Advox. $\quad$ https://advox.globalvoices.org/wp-content/uploads/2017/08/ FreeBasicsinRealLife_FINALJuly27.pdf

[12] Geoffrey C. Bowker. 2008. Memory practices in the sciences (1. paperback ed ed.). MIT, Cambridge, Mass. OCLC: 604636840.

[13] Geoffrey C. Bowker and Susan Leigh Star. 2000. Sorting things out: classification and its consequences (first paperback edition ed.). The MIT Press, Cambridge, Massachusetts London, England. OCLC: 247920023.

[14] Michael Buckland and The Hegeler Institute. 2014. Documentality Beyond Documents:. Monist 97, 2 (2014), 179-186. https://doi.org/10.5840/monist201497212

[15] Earvin Charles Cabalquinto. 2020. [Dis]connected Households: Transnational Family Life in the Age of Mobile Internet. In Second International Handbook of Internet Research, Jeremy Hunsinger, Matthew M. Allen, and Lisbeth Klastrup (Eds.). Springer Netherlands, Dordrecht, 83-103. https://doi.org/10.1007/978-94024-1555-1_64

[16] Miguel Camus. 2020. PH internet deal with Facebook a go by September 2020 - DICT. Philippine Daily Inquirer (May 2020). https://technology.inquirer.net/ 99611/ph-internet-deal-with-facebook-a-go-by-september-2020-dict

[17] J Clement. 2020. Facebook visitor reach leading markets 2020. https://www.statista.com/statistics/278435/percentage- of-selected-countriesinternet-users-on-facebook/

[18] Facebook Connectivity. 2020. Discover Technical Information. https:// connectivity.fb.com/discover-technical-information/

[19] Onofre D. Corpuz. 1997. An economic history of the Philippines. University of the Philippines Press, Quezon City.

[20] Ronald E. Day. 2019. Documentarity: evidence, ontology, and inscription. The MIT Press, Cambridge, MA.

[21] Fahad R. Dogar, Ihsan Ayyub Qazi, Ali Raza Tariq, Ghulam Murtaza, Abeer Ahmad, and Nathan Stocking. 2020. MissIt: Using Missed Calls for Free, Extremely Low Bit-Rate Communication in Developing Regions. In Proceedings of the 2020 CHI Conference on Human Factors in Computing Systems. ACM, Honolulu HI USA, 1-12. https://doi.org/10.1145/3313831.3376259

[22] Paul Dourish, Christopher Lawrence, Tuck Wah Leong, and Greg Wadley. 2020. On Being Iterated: The Affective Demands of Design Participation (CHI '20). Association for Computing Machinery, New York, NY, USA. https://doi.org/10. $1145 / 3313831.3376545$

[23] Hamid Ekbia and Bonnie Nardi. 2016. Social Inequality and HCI: The View from Political Economy. In Proceedings of the 2016 CHI Conference on Human Factors in Computing Systems - CHI '16. ACM Press, Santa Clara, California, USA, 4997-5002. https://doi.org/10.1145/2858036.2858343

[24] Facebook. [n.d.]. About Discover. https://www.facebook.com/help/discover/ 314429429484693/?helpref=hc fnav\&bc[0]=Discover\%20Help

[25] Maurizio Ferraris. 2013. Documentality - Or why nothing social exists beyond the text. From ontos verlag: Publications of the Austrian Ludwig Wittgenstein Society 
- New Series (Volumes 1-18) 3, 0 (Oct. 2013). http://wittgensteinrepository.org/ agora-ontos/article/view/2015

[26] Sheera Frenkel, Nicholas Casey, and Paul Mozur. 2018. In Some Countries, Facebook's Fiddling Has Magnified Fake News. The New York Times (Jan. 2018). https://www.nytimes.com/2018/01/14/technology/facebook-news-feedchanges.html

[27] Genevieve Gebhart. 2016. Zero-rating in emerging mobile markets: Free Basics and Wikipedia Zero in Ghana. In Proceedings of the Eighth International Conference on Information and Communication Technologies and Development - ICTD '16. ACM Press, Ann Arbor, MI, USA, 1-9. https://doi.org/10.1145/2909609.2909663

[28] Tarleton Gillespie. 2018. Custodians of the internet: platforms, content moderation, and the hidden decisions that shape social media. Yale University Press, New Haven. OCLC: on1005113962.

[29] GlobalWebIndex. 2020. Social: GlobalWebIndex's flagship report on the latest trends in social media. Technical Report. GlobalWebIndex. https://www.globalwebindex. com/reports/social

[30] GSMA. 2014. Mark Zuckerberg's keynote appearance at the Mobile World Congress 2014. https://www.youtube.com/watch? $\mathrm{v}=\mathrm{VHwkHZpXqWc \& feature=}$ emb title

[31] GSMA. 2020. The mobile economy 2020. Technical Report. GSMA, London, United Kingdom. https://www.gsma.com/mobileeconomy/wp-content/uploads/2020/ 03/GSMA_MobileEconomy2020_Global.pdf

[32] Jessi Hempel. 2018. What Happened to Facebook's Grand Plan to Wire the World? Wired (May 2018). https://www.wired.com/story/what-happened-tofacebooks-grand-plan-to-wire-the-world/ 2012-12-11.

[33] Lilly Irani. 2018. The Good Fight. New Scientist (Dec 2018), 24-25.

[34] Carlee Joe-Wong, Soumya Sen, and Sangtae Ha. 2018. Sponsoring Mobile Data: Analyzing the Impact on Internet Stakeholders. IEEE/ACM Transactions on Networking 26, 3 (June 2018), 1179-1192. https://doi.org/10.1109/TNET.2018. 2826531

[35] Simon Kemp. 2020. Digital 2019: Global digital overview. Technical Report. https://datareportal.com/reports/digital-2020-global-digital-overview

[36] Chen Kuang-Jung. 1997. The sari-sari store: informal retailing in the Philippines. fournal of Small Business Management 35, 4 (Oct. 1997), 88-91.

[37] Ronald Ravinesh Kumar. 2013. Linking remittances with financial development and ICT: a study of the Philippines. International fournal of Economics and Business Research 5, 4 (2013), 379. https://doi.org/10.1504/IJEBR.2013.054254

[38] Roslyn Layton and Silvia Elaluf-Calderwood. 2016. Free Basics Research Paper Zero Rating, Free Data, and Use Cases in mhealth, Local Content and Service Development, and ICT4D Policymaking. TPRC 44: The 44th Research Conference on Communication, Information and Internet Policy 2016 (2016). https://doi.org/ $10.2139 /$ ssrn. 2757384

[39] Daniel P. Lopresti and A. Lawrence Spitz. 2005. Information leakage through document redaction: attacks and countermeasures, Elisa $\mathrm{H}$. Barney Smith and Kazem Taghva (Eds.). San Jose, CA, 183-190. https://doi.org/10.1117/12.589552

[40] Niels Windfeld Lund. 2010. Document, text and medium: concepts, theories and disciplines. Fournal of Documentation 66, 5 (Sept. 2010), 734-749. https: //doi.org/10.1108/00220411011066817

[41] Ty Matejowsky. 2007. Convenience store Pinoy: Sari-sari, 7-eleven, and retail localization in the contemporary Philippines. Philippine Quarterly of Culture and Society 35,4 (2007), 247-277.

[42] Nicolas Mirabaud. 2009. Migrants' remittances and mobile transfer in emerging markets. International fournal of Emerging Markets 4, 2 (April 2009), 108-118. https://doi.org/10.1108/17468800910945756

[43] Mary Grace Mirandilla-Santos, Jonathan Brewer, and Jaime Faustino. 2018. From Analog to Digital: Philippine Policy and Emerging Internet Technologies. Technical Report. The Asia Foundation. http://hdl.handle.net/11540/9428

[44] Anjali Nath. 2014. Beyond the Public Eye: On FOIA Documents and the Visual Politics of Redaction. Cultural Studies $\leftrightarrow$ Critical Methodologies 14, 1 (Feb. 2014), 21-28. https://doi.org/10.1177/1532708613507885

[45] ABS-CBN News. 2014. Why Globe ended free Facebook mobile service. https://news.abs-cbn.com/business/05/08/14/why-globe-ended-freefacebook-mobile-service

[46] Toussaint Nothias. 2020. Access granted: Facebook's free basics in Africa. Media, Culture \& Society 42, 3 (April 2020), 329-348. https://doi.org/10.1177/ 0163443719890530

[47] Benedict Salazar Olgado, Lucy Pei, and Roderic Crooks. 2020. Determining the Extractive Casting Mold of Intimate Platforms through Document Theory. In Proceedings of the 2020 CHI Conference on Human Factors in Computing Systems. ACM, Honolulu HI USA, 1-10. https://doi.org/10.1145/3313831.3376850

[48] Bernt Ivar Olsen, Niels Windfeld Lund, Gunnar Ellingsen, and Gunnar Hartvigsen 2012. Document theory for the design of socio-technical systems: A document model as ontology of human expression. Fournal of Documentation 68, 1 (Jan 2012), 100-126. https://doi.org/10.1108/00220411211200347

[49] Jonathan Corpus Ong. 2019. When Disinformation Studies Meets Production Studies: Social Identities and Moral Justifications in the Political Trolling Industry. (2019), 20.

[50] Jonathan Corpus Ong and Jason Vincent Cabañes. [n.d.]. Architects of Networked Disinformation: Behind the Scenes of Troll Accounts and Fake News Production in the Philippines. Technical Report. University of Massachusetts Amherst. https: //doi.org/10.7275/2CQ4-5396

[51] Michael Palacios. 2014. Internet in the Philippines: 20 years since. https: //rappler.com/technology/features/internet-philippines-20-years

[52] Richard Pearce-Moses. 2005. A glossary of archival and records terminology. Society of American Archivists, Chicago.

[53] Lucy Pei and Roderic Crooks. 2020. Attenuated Access: Accounting for Startup, Maintenance, and Affective Costs in Resource-Constrained Communities. In Proceedings of the 2020 CHI Conference on Human Factors in Computing Systems. ACM, Honolulu HI USA, 1-15. https://doi.org/10.1145/3313831.3376587

[54] Amreesh Phokeer, Melissa Densmore, David Johnson, and Nick Feamster. 2016. A First Look at Mobile Internet Use in Township Communities in South Africa. In Proceedings of the 7th Annual Symposium on Computing for Development. ACM, Nairobi Kenya, 1-10. https://doi.org/10.1145/3001913.3001926

[55] Vicente L. Rafael. 2019. The Sovereign Trickster. The fournal of Asian Studies 78, 1 (Feb. 2019), 141-166. https://doi.org/10.1017/S0021911818002656

[56] Ramneek, Patrick Hosein, and Sungin Jung. 2019. A Network Neutral Alternative to Free Basics. In Internet Science (Lecture Notes in Computer Science), Samira El Yacoubi, Franco Bagnoli, and Giovanna Pacini (Eds.). Springer International Publishing, Cham, 189-203. https://doi.org/10.1007/978-3-030-34770-3_14

[57] Sarah T. Roberts. 2019. Behind the screen: content moderation in the shadows of social media. Yale University Press, New Haven. OCLC: on 1055263168.

[58] Julianne Romanosky and Marshini Chetty. 2018. Understanding the Use and Impact of the Zero-Rated Free Basics Platform in South Africa. In Proceedings of the 2018 CHI Conference on Human Factors in Computing Systems - CHI '18. ACM Press, Montreal QC, Canada, 1-13. https://doi.org/10.1145/3173574.3173766

[59] Romeo Agan Salac and Yun Seon Kim. 2016. A Study on The Internet Connectivity in The Philippines. Asia Pacific fournal of Business Review 1, 1 (Aug. 2016), 67-88. https://doi.org/10.20522/APJBR.2016.1.1.67

[60] Salleh. 2015. Internet.Org is now Facebook Free Basics, partners with Globe in the PH. https://www.adobomagazine.com/archived/internet-org-is-nowfacebook-free-basics-partners-with-globe-in-the-ph/

[61] Chris Schnabel. 2015. Internet.org reboots: What it means for PH. https: //rappler.com/business/internet-org-free-basics-facebook

[62] Rijurekha Sen, Sohaib Ahmad, Amreesh Phokeer, Zaid Ahmed Farooq, Ihsan Ayyub Qazi, David Choffnes, and Krishna P. Gummadi. 2017. Inside the Walled Garden: Deconstructing Facebook's Free Basics Program. ACM SIGCOMM Computer Communication Review 47, 5 (Oct. 2017), 12-24. https: //doi.org/10.1145/3155055.3155058

[63] Rijurekha Sen, Hasnain Ali Pirzada, Amreesh Phokeer, Zaid Ahmed Farooq, Satadal Sengupta, David Choffnes, and Krishna P. Gummadi. 2016. On the Free Bridge Across the Digital Divide: Assessing the Quality of Facebook's Free Basics Service. In Proceedings of the 2016 ACM on Internet Measurement Conference IMC '16. ACM Press, Santa Monica, California, USA, 127-133. https://doi.org/10. 1145/2987443.2987485

[64] Clay Shirky. 2003. Power laws, weblogs, and inequality. (2003).

[65] SimilarWeb. [n.d.]. How does SimilarWeb categorise domains? http://support. similarweb.com/hc/en-us/articles/360001253737

[66] SimilarWeb. [n.d.]. Our Data. https://www.similarweb.com/corp/ourdata/

[67] Siddharth Singh, Vedant Nanda, Rijurekha Sen, Satadal Sengupta, Ponnurangam Kumaraguru, and Krishna P. Gummadi. 2017. Leveraging Facebook's Free Basics Engine for Web Service Deployment in Developing Regions. In Proceedings of the Ninth International Conference on Information and Communication Technologies and Development (ICTD '17). Association for Computing Machinery, Lahore, Pakistan, 1-11. https://doi.org/10.1145/3136560.3136568

[68] Olle Sköld. 2013. Tracing traces: A document-centred approach to the preservation of virtual world communities. Information Research 18, 3 (2013). http: //lup.lub.lu.se/record/4330098 Publisher: Professor TD Wilson.

[69] Daniel Smith-Rowsey. 2016. Imaginative indices and deceptive domains: How Netflix's categories and genres redefine the long tail. In The Netflix effect : technology and entertainment in the 21st century (1st ed.). Bloomsbury Publishing Inc, New York, NY, 63-80.

[70] Internet World Stats. [n.d.]. Asia Internet Usage Stats Facebook and 2020 Population Statistics. https://www.internetworldstats.com/stats3.htm

[71] Jake Swearingen. 2018. Facebook Used the Philippines to Test Free Internet. Then a Dictator Was Elected. https://nymag.com/intelligencer/2018/09/howfacebooks-free-internet-helped-elect-a-dictator.html

[72] Jake Swearingen. 2018. In Seeking to Stop Fake News, Facebook Killed Real News. https://nymag.com/intelligencer/2018/01/in-seeking-to-stop-fake-newfacebook-killed-real-news.html

[73] Edson C Tandoc and Bruno Takahashi. 2017. Log in if you survived: Collective coping on social media in the aftermath of Typhoon Haiyan in the Philippines. New Media \& Society 19, 11 (Nov. 2017), 1778-1793. https://doi.org/10.1177/ 1461444816642755

[74] Jenni Tupuna Uimonen. 2020. "Who could possibly be against this?" - Mark Zuckerberg's framing of connectivity in the context of Free Basics. Thesis. University of Helsinki. https://helda.helsinki.fi/bitstream/handle/10138/311441/Uimonen_ 
Jenni_Pro gradu 2020.pdf?sequence=2\&isAllowed $=y$

[75] Cecilia S. Uy-Tioco. 2019. 'Good enough' access: digital inclusion, social stratification, and the reinforcement of class in the Philippines. Communication Research and Practice 5, 2 (April 2019), 156-171. https://doi.org/10.1080/22041451.2019. 1601492

[76] Anton Vera. 2017. The impact of the Philippine ISP duopoly on mobile broadband adoption. Ph.D. Dissertation. Stanford University, Stanford, CA. https://economics.stanford.edu/sites/g/files/sbiybj9386/f/publications/vera anton_honors_thesis_3-13-17.pdf

[77] Thomas J. Weinandy. 2016. Volunteer and Technical Communities in Humanitarian Response: Lessons in Digital Humanitarianism from Typhoon Haiyan. UN Chronicle 53, 1 (June 2016), 29-30. https://doi.org/10.18356/f22a27d6-en

[78] JungAe Yang. 2016. Effects of Popularity-Based News Recommendations ("MostViewed") on Users' Exposure to Online News. Media Psychology 19, 2 (Apri
2016), 243-271. https://doi.org/10.1080/15213269.2015.1006333

[79] Moonjung Yim, Ricardo Gomez, and Michelle S. Carter. 2016. Facebook's "Fre Basics": For or against community development? The fournal of Community Informatics 12,2 (2016). ISBN: 1712-4441.

[80] Jennifer Zamora. 2020. 28 Days Later: New Internet Users in Brazil and India Try a Lite Smartphone for a Month. In Proceedings of the 3rd ACM SIGCAS Conference on Computing and Sustainable Societies. ACM, Ecuador, 53-64. https: //doi.org/10.1145/3378393.3402247

[81] Yoav Zeevi. 2020. Facebook introduces Discover: Exploring new ways to support connectivity. https://tech.fb.com/discover/ Library Catalog: tech.fb.com.

[82] Mark Zuckerberg. 2013. Is Connectivity a Human Right? https://www.facebook. com/isconnectivityahumanright 